medical officers (although, I confess, there is much yet to reform in this respect), and the frequency of periodical examinations by some of the teachers, may also be acided to the list of benefits on the part of the student which have been reluctantly oitained from the "Dubs and Pures."

The above changes, however, are unimportant compared with those which ought long since to have been adopted. The present system of electing medical officers to our hospitals and dispensaries, I consider to be a disgrace to the country, and until the election by "concours" be introduced, we must remain, in a scientific point of view, inferior to our continental brethren. I may be told that "some of our hospital surgeons and physicians have contributed largely to the advancement of medical science;" but, let me ask, have they done so in proportion to the opportunities afforded them? I reply that for one urrking bee we have had ten drones, and it is no answer to my question to tell me that the soil has "sometimes been fertile," when, if properly cultivated, it might always have yielded a plentiful harvest.

The next evil which cries loudly for re. dress is the system of electing dressers, who are selected, not on account of their superior qualifications for the office, but because they are enabled to pay a large fee to the surgeon; any man who is at all acquainted with a public hospital, must have witnessed the frequent injury to the patient in consequence of the inexperience of these tyros. Now, Sir, if the surgeons would abolish the present mercenary system, and, by public examination, select those students who are found to be most competent for the office, they would confer a great boon upon suffering humanity, both by ensuring a better attendance upon the sick, and by exciting a laudable emulation amongst the younger members of our profession.

The absence of a resident operating surgeon at the hospital is, I believe, another cause of the annual sacrifice of life. The following is not an imaginary case, and one not of unfrequent occurrence :-A poor man is taken to the hospital labouring under strangulated hernia, or some other danger. ons disease, and, after being subjected to the tender touch of a host of dressers, a messenger is sent off to Mr. - - who resides three or four miles from the hospital, and who, perhaps, at the time, is at a greater distance from his own residence; so that some hours are lost before his arrival, and sometimes the patient also is lost in consequence of the delay.

1 might enumerate many other abuses which demand correction, but they have been so often noticed in your pages, that $I$ need not repeat them. They are, however, I conceive, all dependant upon the present system of medical misgovernment, and will continue to exist until we obtain elections by "Concours" and a Tripartite Faculty of Medicine. This once accomplished, the system of nepotism and jobbing at our public hospitals will necessarily cease; and we shall not then see men who (to use the language of Dr. South) "would have done their country greater service at the plough's tail," filling situations requiring assiduity and talent. Your obedient servant, Sept. 14, 1837.

SPletator.

\section{DR. JOHNSON'S REPLY TO DR. DICKSON.}

\section{To the Editor of THe LanceT.}

SrR :-Having given place to Dr. Dick. son's long and abusive article, I claim your indulgence for the insertion of a very short reply. He says he is in a condition to prove, that I not only "s take, but demand," fees from medical practitioners. I dare him to the proof. I never demanded a fee from any human being in my life, and $I$ have invariably refused fees from medical practitioners, uhen I knew them to be medical. I have ascertained that a few medical men, who were utter strangers to me, have consulted me without letting me know their avocation, probably from some erroneous impression that a more candid opinion would be given to them. This is surely no subject of accusation against me. There are hundreds, or rather thousands, of practitioners in this country, the colonies, and America, who could, and I think many of them will, contradict this slanderous aspersion of Dr. Dickson.

In respect to servants, I certainly do not proclaim gratuitous advice to them, in order to catch stray fees from their masters. It is possible, that a fashionable lady's maid, who has caught the airs as well as the vapours of her mistress, may occasionally fee me for my advice, without my being able to discriminate her rank in life; but, without making any parade of my liberality, it is just possible that $I$ am as little inclined to wring money from the hands of the poor as my accuser.

Dr. Dickson's rabid ravings against pathology, the lancet, and the stethoscope, prove him to be inattentive to, if not ignorant of, some of the most important means we possess of improving our profession. As to his theory, if it ceserve such a name, its only redeeming quality is its matchless absurdity, which, in despite of its intolerance and bigotry, must convulse every reader with laughter at the brain that could engender such a chaos of crudities, such a perversion of reasoning, and such a labyrinth of errors. I am, Sir, your obedient servant,

Sept. 25, 1837. 